\title{
LA CAPILLA MAYOR DE LA IGLESIA DE SAN JUAN DE BAZA (GRANADA)
}

\author{
JUAN MANUEL SEGURA FERRER \\ Universidad de Granada
}

Fecha de recepción: 08/07/2021

Fecha de aceptación: 23/10/2021

\section{Resumen}

La iglesia de San Juan, singular edificio del siglo XVI, supone en su conjunto una manifestación destacada del tránsito de la arquitectura tardogótica a la renacentista en el norte del Reino de Granada. La capilla mayor, el espacio más antiguo y relevante del templo, al que dedicamos este artículo, fue el primero en construirse, en el primer tercio del siglo XVI, levantando su retablo a finales de dicha centuria.

\section{Palabras clave}

Siglos XVI-XVIII. Arquitectura y retablística. Tardogótico, Renacimiento y Barroco. Iglesia de San Juan. Baza. Maestros de cantería, entalladores, escultores, tallistas, pintores, doradores. Juan Caballero, Rodrígo de Lamíquiz, Juan de Mújica, Pedro de Guía, Gabriel y Miguel de Freila, Juan Antonio y Pedro Montoro

\section{THE MAJOR CHAPEL OF SAN JUAN DE BAZA'S CHURCH (GRANADA)}

\section{Summary}

The church of San Juan, a unique building of the sixteenth century, represents as a whole an outstanding manifestation of the transit from late Gothic architecture to renaissance architecture in the north of the Kingdom of Granada. The main chapel, the oldest and most relevant space of the temple, to which we dedicate this article, was the first to be built, in the first third of the sixteenth century, raising its altarpiece at the end of that century.

\section{Key words}

XVI-XVIII centuries. Architecture and retablistic. Late Gothic, Renaissance and Baroque. St. John's Church. Baza. Masters of stonework, notchers, sculptors, tallists, painters, gilters. Rodrígo de Lamíquiz, Juan de Mújica, Pedro de Guía, Gabriel and Miguel de Freila, Juan Antonio and Pedro Montoro. 


\section{Introducción}

Tras la conquista de Baza por los Reyes Católicos la población musulmana se confinó en el barrio de San Juan, convirtiéndose la mezquita principal del arrabal en iglesia cristiana, siendo erigida como parroquia después de la conversión general de moriscos en 1505. Como afirma el historiador Javier Castillo la advocación del templo debe relacionarse con el deseo de evangelizar a la comunidad musulmana bastetana, la cual constituía a comienzos del siglo XVI el noventa por ciento de la población de este importante barrio.

Con el paso del tiempo el número de habitantes del arrabal creció considerablemente, tanto por el proceso natural como por el movimiento de emigración de moriscos de otras zonas, especialmente de la comarca del río Almanzora (Almería). Ante tal aumento de población se construyeron nuevas calles para acogerlos en solares cedidos a censo por la ciudad y por miembros de la oligarquía local y fue en una de estas vías dónde se construyeron los baños de Gonzalo de Quirós o de la Morería, levantados alrededor de 1517 en la parte alta del arrabal para abastecer a los moriscos bastetanos ${ }^{1}$.

\section{La construcción del templo}

La actual iglesia de San Juan es el resultado de tres fases constructivas desarrolladas a lo largo del siglo XVI. La primera, de la que sólo se conserva la capilla mayor, se llevó a cabo en el primer tercio del quinientos, muy probablemente en la década de los años veinte.

Tras el asolador seísmo de 1531, y el hundimiento de la mayoría de las construcciones religiosas de la ciudad, los maestros que realizaron la primera inspección sobre el estado en el que se encontraba el templo emitieron un dictamen, diferenciando las dos partes principales del inmueble. Estimaron que los reparos que necesitaba la capilla mayor se podían realizar con 90.000 maravedíes, aunque era difícil precisar más sin una exploración detallada. Si al final se tuviesen que desmontar todos los paramentos de cantería serían necesarios más de 250.000 maravedíes para levantarla de nuevo. Según los peritos el resto de la iglesia, el cuerpo de naves, quedó en pésimo estado de conservación, previendo que sería necesario reconstruirlo desde los cimientos, con un coste inicial de 360.000 maravedíes, hecho que se materializó en las décadas centrales del siglo².

A principios de la década de los cuarenta tenemos la segunda fase de edificación del templo. En 1542 comenzaba a levantarse la capilla privada más destacada, la situada junto al presbiterio, propiedad de Álvaro de Alcaraz, miembro de una de las familias judeoconversas más poderosas de la ciudad ${ }^{3}$.

La última fase constructiva se realizó en las décadas centrales de dicha centuria, en los años cincuenta y sesenta, momento en el que se levantó el cuerpo de naves y la torre ${ }^{4}$. Desconocemos el motivo por el que se tardó casi una década en cubrir las naves con techumbres de madera policromada, comenzando las obras en 1562. Los trabajos debieron ralentizarse por falta de caudales, algo habitual en la Baza de la Edad Moderna.

Un rasgo distintivo de la concepción de las cubiertas de éste, y de otros templos bastetanos, es el marcado contraste entre las bóvedas de crucería tardogóticas de la capilla mayor y las techumbres de madera del resto de la iglesia, actualmente tapadas bajo un doble techo. Esta

\footnotetext{
${ }^{1}$ Segura/Valero, 2009: 61-83.

${ }^{2}$ Este trabajo es el cuarto eslabón en la elaboración de un futuro libro sobre la iglesia de San Juan de Baza que estamos preparando.

4 Segura/Valero, 2015: 145-165.

${ }^{4}$ Desconocemos si la construcción de la torre se quedó a medias.
} 
tipología es bastante habitual en el siglo XVI, momento en el que se produce una verdadera indefinición artística, dando lugar a la hibridación característica del quinientos español.

Tras realizar una descripción general del proceso de construcción del templo nos centraremos en la capilla mayor, dejando el cuerpo de naves y las techumbres de madera policromada que las cubrieron pues su estudio se realizó en artículos anteriores ${ }^{5}$.

\section{La capilla mayor}

La propuesta de levantar el nuevo templo surgió ante la necesidad de renovar la antigua mezquita transformada en iglesia y posiblemente por la escasa capacidad para acoger al creciente número de asistentes por el elevado aumento demográfico del barrio, dónde se concentraba gran parte de la población morisca de la ciudad al establecerse, en su parte alta, la Morería bastetana.

Según Javier Castillo la iglesia de San Juan fue la primera que se erigió de nueva planta en la ciudad, comenzando las obras por la capilla mayor, conservando la misma orientación de la antigua mezquita, sur-sureste, dirección que seguían los musulmanes para dirigirse a la $\mathrm{Meca}^{6}$. La favorable coyuntura económica de la primera mitad del siglo XVI permitió la construcción de nuevas iglesias, más amplias y luminosas, sustituyendo a las pequeñas y oscuras mezquitas. Todo ello auspiciado en las directrices de la política del cardenal Cisneros, las de sustituir los lugares de culto musulmán por cristianos.

Mientras se tomaba la decisión de la construcción definitiva se realizaron distintas obras y remodelaciones en la antigua mezquita. Lo documentado hasta el momento es que desde 1511 la corona comenzó a aportar dinero para levantar las iglesias del Reino de Granada ${ }^{7}$. El abad Pedro Montano declaraba, en testamento otorgado en enero de 1513, que había mandado edificar los arcos y el coro de San Juan ${ }^{8}$. En las actas municipales de 1518 se afirmaba que se estaban realizando obras en la torre y en la entrada del templo9. La capilla mayor debió construirse poco después, probablemente a comienzos de los años veinte.

Aunque Javier Castillo afirma que los trabajos comenzaron en torno a $1512^{10}$ (basándose en las declaraciones de varios canteros en un juicio del 1540) ${ }^{11}$, intuimos que es una obra posterior, de principios de la década de los años veinte. Si tenemos en cuenta las construcciones similares levantadas por esos años, con las que mantiene bastantes similitudes, y la escasa documentación aparecida hasta el momento, apuntamos a que se edificó a principios de la década de los veinte.

\footnotetext{
${ }^{5}$ Segura/Valero, 2014: 385-399 y Segura/Valero, 2015: 323-337.

${ }^{6}$ Castillo, 2009: 165.

${ }^{7}$ Magaña, 1996: 262-263. No han aparecido hoy en día documentos que clarifiquen quién fue el tracista y el ejecutor de esta construcción. Según la carta de Repartimiento, otorgada el 9 de septiembre de 1513, la Corona cedía cierta cantidad de dinero anual para la edificación y conservación de las iglesias de la Abadía de Baza, correspondiéndole al templo de San Juan cuatro mil maravedíes anuales. Cantidad que debía recibir desde 1511.

${ }^{8}$ Magaña, 1996: 223.

${ }^{9}$ Martínez/Tristán, 2004: 45.

${ }^{10}$ Castillo, 2009: 165. De haberse trazado y comenzado a construir en este periodo (1512/1516), señalar la presencia del cantero Juan Caballero, de probable origen murciano, quién inició el levantamiento del puente sobre el río Barbata y debió dirigir otras obras destacadas a nivel civil y religioso.

${ }^{11}$ Archivo de la Real Chancillería de Granada (ARCHGR). En un pleito de 1540 varios maestros de cantería declaran que la construcción del templo se realizó entre veinte y veinticinco años atrás. Aunque muchos de los declarantes mencionan que la iglesia se construyó hacía veinte años atrás, hay algunos que afirman que se levantaría hacia unos veinticinco años.
} 
Un dato revelador es que en 1523 estaba trabajando en la iglesia el maestro de cantería Rodrígo de Lamíquiz. El 16 de julio de ese año, siendo vecino de Guernica, en el señorío de Vizcaya, daba un poder a otros canteros asentados en Baza para que cobrasen los 24.000 maravedíes que le debía el mayordomo de dicha parroquia por los trabajos realizados, quizás los de la construcción de la capilla mayor ${ }^{12}$. En dicha escritura su nombre iba precedido de la palabra maestre, confirmando que estamos ante un maestro maduro, con reconocida experiencia en el mundo de la cantería.

A falta de más datos que ayuden a identificar al tracista de esta capilla dirigimos nuestra mirada a Rodrigo de Lamíquiz, maestro que debió llegar a Baza a principios de la década de los años veinte. En Yeste (Albacete) se encontraba trabajando cuando el ayuntamiento bastetano acordaba llamarlo (3/10/1521) con la finalidad de que se presentase en la ciudad y emitiera un informe y propuesta sobre las obras a realizar en el puente Barbata ${ }^{13}$. Tras su asentamiento temporal en la urbe el cabildo abacial debió encargarle proyectos tanto en iglesias locales, caso de la de San Juan, como en las de varias villas pertenecientes a su Abadía, las parroquiales de Cúllar y Orce, hecho que queda reflejado en su petición, de julio de 1523, al solicitar se le pagasen las intervenciones realizadas en estas tres poblaciones.

Como hemos comentado anteriormente la iglesia de San Juan se mantuvo en buen estado hasta el gran seísmo de 1531, produciéndose diversas grietas, motivo por el cual tuvo que ser intervenida, necesitando algunas obras, actuaciones realizadas, entre otros, por el cantero Pedro de Guía ${ }^{14}$.

Un eco o la correspondencia gemela de esta construcción lo encontramos en la capilla mayor de la iglesia de Nuestra Señora de la Asunción de Hornos de Segura (Jaén), levantada a partir de 1523, pudiéndose establecer una relación estilística más que evidente entre ambas construcciones, contando con escasas diferencias ${ }^{15}$. La presencia de diseños tan similares sugiere la hipótesis de su elaboración por un mismo maestro, con trazas propias, que en el fondo siguen las líneas generales de lo que se está construyendo en este periodo en el sudeste, pero introduciendo pequeñas variantes diferenciadas para poder hacerlas únicas.

En ambas capillas se sigue idéntica planta y tipo de pilares ${ }^{16}$, con basas y capiteles góticos decorados con bolas, una única y similar ventana ${ }^{17}$, la misma tipología de bóveda y alero externo con un perlario de bolas góticas, elementos todos ellos que sugieren la intervención de un mismo maestro o artífice cercano.

Sendas capillas se están edificando en un mismo periodo, en el primer tercio del siglo $\mathrm{XVI}^{18}$. El análisis pormenorizado de cada uno de los elementos que integran esta notable construcción ocupara nuestra descripción.

\footnotetext{
${ }^{12}$ Archivo de Protocolos de Granada (APG), Baza, Diego de Ahedo, 1523, ff.191-191v. Poder del maestre Rodrigo de Lamíquiz.

13 Tristán, 2016: 8-89.

${ }^{14}$ Castillo, 2009: 165.

${ }^{15}$ Las dos capillas tan sólo disponen de una sola ventana de parecido formato, en vez de las dos habituales.

${ }^{16}$ Sorprende que las semicolumnas de la cabecera no están presentes. Los nervios de la bóveda arrancan de los capiteles, los cuales quedan suspendidos como si de ménsulas se tratara.

${ }^{17}$ Aunque las ventanas están dispuestas en distinta ubicación, la de Hornos en el lado de la Epístola y la de Baza en el de Evangelio.

${ }^{18}$ Si la capilla de Baza fuese una obra anterior, de mediados de la primera década, entre 1512-1515, podría ser diseño del cantero Juan Caballero.
} 


\section{Análisis estilístico}

El presbiterio se levantará siguiendo un planteamiento constructivo y decorativo propio del tránsito entre el último Gótico y el primer Renacimiento, estilo mixto caracterizado por el empleo de elementos tardogóticos presentes en las semicolumnas (basas y capiteles) y en la espléndida bóveda, empleando otros recursos que anuncian la llegada del nuevo estilo: el arco de medio punto y la utilización de una cabecera cuadrada. Hasta la década de 1530, y aún después, en la arquitectura española no terminó de imponerse lo romano.

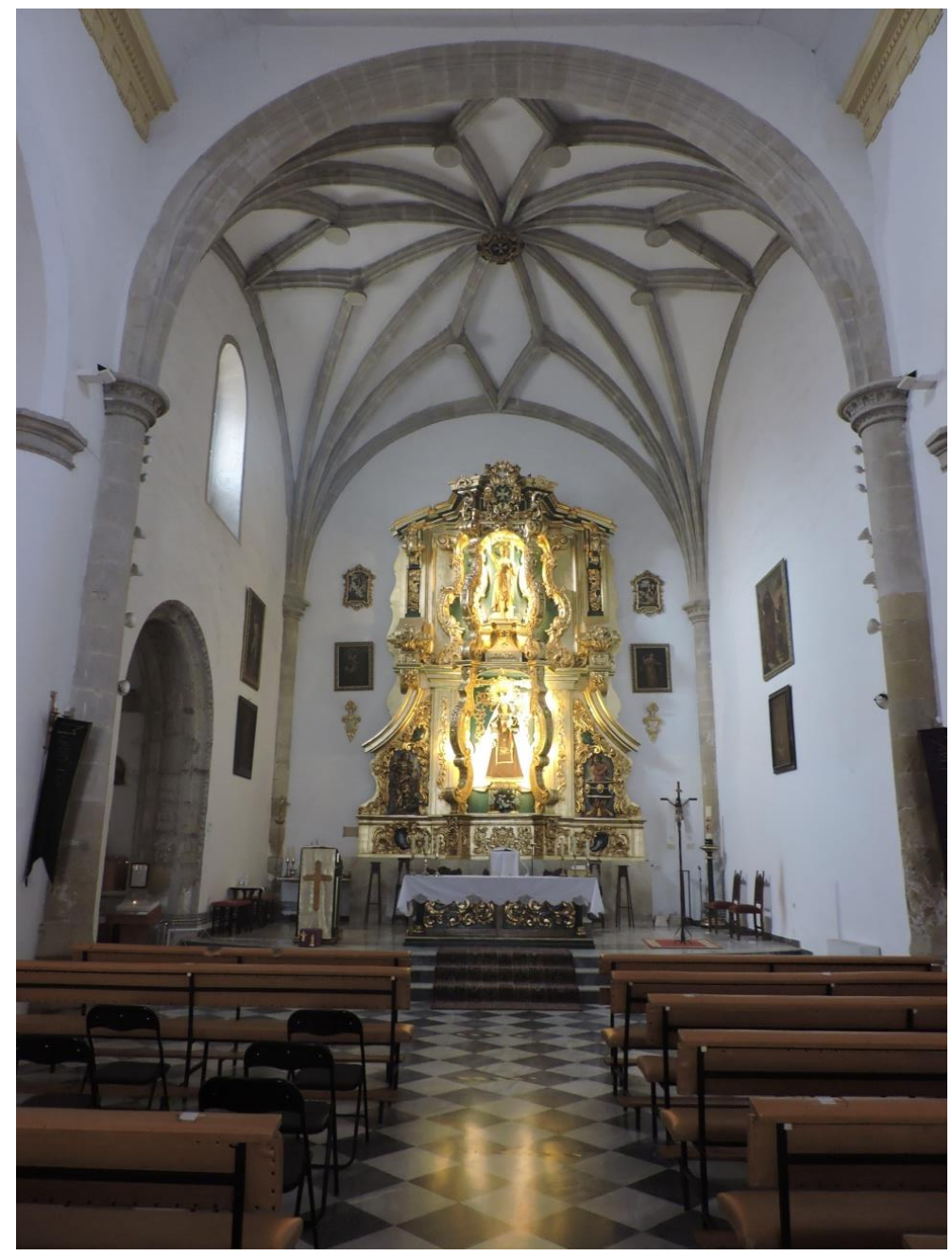

Fig. 1. Vista general de la capilla.

Un dato significativo con respecto a la planta es la utilización de una cabecera de formato cuadrangular, más acorde con los nuevos planteamientos del siglo XVI, dejando a un lado los diseños poligonales bajomedievales que se extendieron hasta la década de los treinta en numerosos templos bastetanos: iglesia colegial de Santa María (1533) y las conventuales de San Jerónimo (1535), San Francisco y primer proyecto de la Merced (1534). 
A partir del último tercio del siglo XV, durante el Gótico tardío, se va a producir un gran desarrollo de las cabeceras, convirtiéndose en las partes más destacadas de los templos, resultado construcciones macrocéfalas, manifestando la grandiosidad de las nuevas iglesias cristianas, caracterizadas, muchas de ellas, por su solidez estructural, amplitud, potentes soportes y sobriedad a nivel decorativo.

Un rasgo que la diferencia del resto de las capillas mayores de cantería de la Baza de la primera mitad del siglo XVI es la ausencia de la línea de imposta que se impuso en las construcciones levantadas a partir de la década de los años treinta ${ }^{19}$.

La capilla, de planta cuadrada, es el espacio más monumental, simbólico y mimado del templo por sus dimensiones y decoración. Está configurada por cuatro semicolumnas adosadas a las esquinas, con basamentos y capiteles góticos, sobre los que descansan tanto los arcos de medio punto como los nervios que configuran la potente bóveda que la cubre.

Estamos ante la última fase de evolución del soporte gótico, simplificado, suprimiéndole el costoso y laborioso baquetonado del siglo XV, coronándolo por un capitel del mismo estilo, descrito, a finales del siglo XIX, como de extraña labor por el ilustre historiador Gómez Moreno $^{20}$. De esta tipología a la renacentista solo hay un paso, basta añadirle unas molduras que sirvan de anillos decorativos en las basas y capiteles siguiendo los órdenes, formatos generalizados en Baza tras el devastador terremoto de 1531 con los proyectos de Alonso de Covarrubias, Diego de Siloé y Rodrigo de Gibaja.

Aunque estamos ante una tipología extendida en varias comarcas de provincias limítrofes del sudeste español, la equivalencia más cercana, en cuanto al uso de la misma planta, tipología de pilar e idéntica bóveda, la tenemos en la iglesia parroquial de Hornos de Segura ${ }^{21}$, construcción con la que mantiene bastantes paralelismos.

Las basas, poligonales y seccionadas, se identifican con las usadas en el último Gótico, visibles en la iglesia recientemente comentada y en la mayoría de los templos de las encomiendas santiaguistas de la Sierra de Segura, caso de Socovos ${ }^{22}$. Se da la circunstancia de que durante este periodo era comendador de esta última villa Enrique Enríquez de Velasco (1482-1525), conde de Ribadabía, sobrino de Enrique Enríquez de Guzmán, el cabeza de la principal familia asentada en Baza tras la Reconquista, comendador que había sido de la orden de Santiago.

En este punto cabe señalar que en esta encomienda, y en las limítrofes, trabajó el cantero Rodrigo de Lamíquiz, hecho que pudo favorecer que lo recomendaran a sus familiares en Baza o simplemente comentaran lo satisfechos que estaban con su trabajo. Los Enríquez-

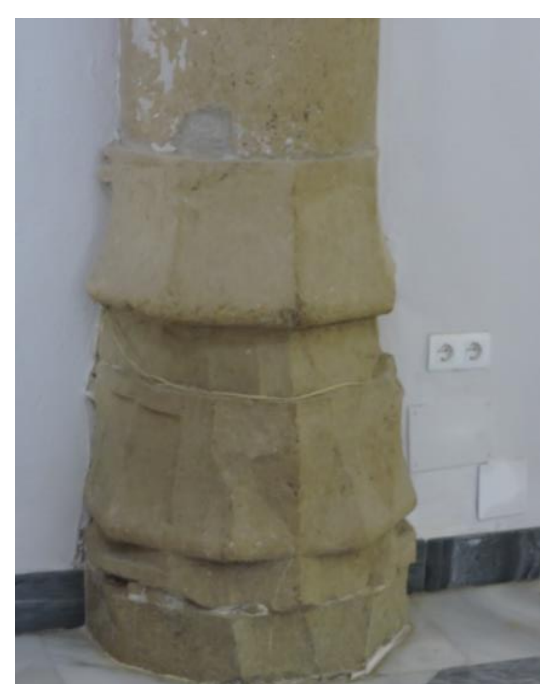

Fig. 2. Basas de las semicolumnas.

${ }^{19}$ Tan sólo contamos con algunas capillas particulares que no disponen de dicho elemento, las que debieron ser trazadas con anterioridad al terremoto de 1531, manteniendo la esencia de su primitivo diseño en su reconstrucción tras el seísmo, caso de la capilla de Juan Romero en la parroquial de Santiago y las capillas de la girola de la iglesia colegial.

${ }^{20}$ Instituto Gómez Moreno (IGM, Granada), Legajo CXXVII, nº 2138.

${ }^{21}$ Sánchez, 2002: 210.

${ }^{22}$ Galera, 1989: 57. En las iglesias parroquiales de la encomienda de Socovos pueden apreciarse rasgos comunes, unos característicos de la orden santiaguista, otra consecuencia de su pertenencia al conjunto de 
Luna eran partidarios de sugerir y escoger a maestros destacados para la realización de las obras relevantes, tanto de la ciudad como las relacionadas con sus fundaciones más importantes. En 1529 don Enrique Enríquez, el III, se ofrecía a intentar localizar a Francisco Florentín con el objetivo de que viniese a dirigir la construcción de la colegiata bastetana, desconociendo que dicho artífice ya había fallecido ${ }^{23}$.

Será en los capiteles dónde se concentre la escasa decoración esculpida, un tambor cónico con dos bandas horizontales engalanadas con bolas y motivos vegetales, siguiendo una solución usual en la mayoría de los reinos de la península ibérica, muy habitual en los territorios de la orden militar de Santiago.

Mientras las dos bandas de los capiteles de las semicolumnas adosadas a las esquinas de la cabecera repiten el mismo motivo, bolas góticas, los situados en los capiteles ubicados junto a la nave principal están decorados por diminutas bolas en su banda inferior y hojas en la superior.

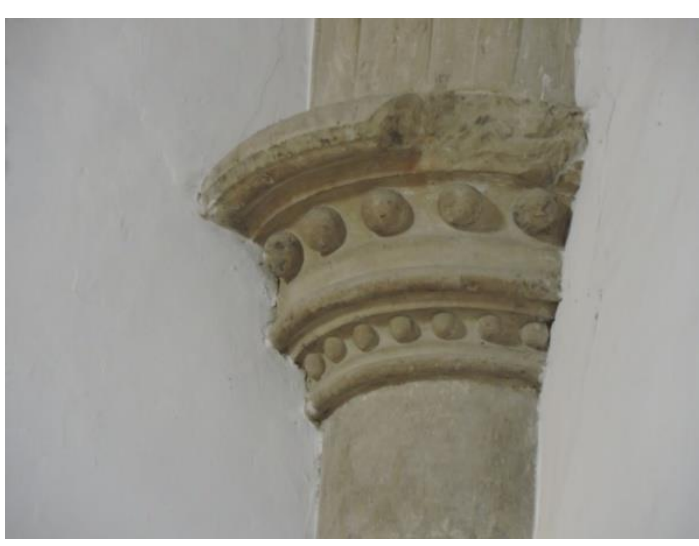

Fig. 3. Capiteles de las semicolumnas.

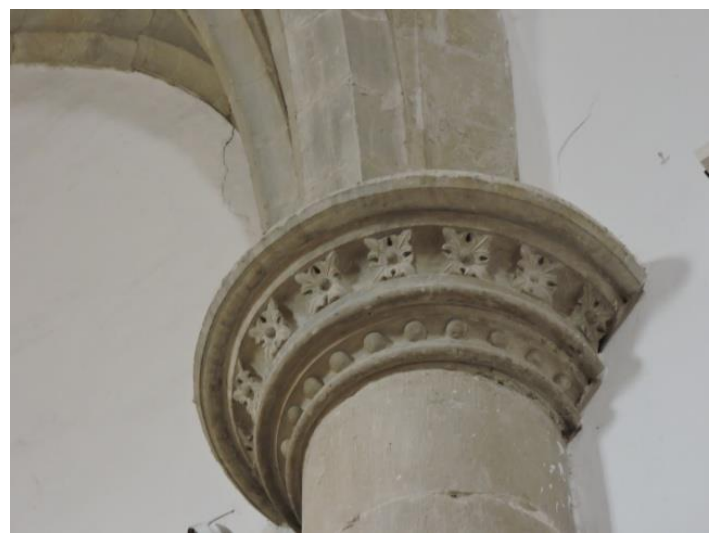

Fig. 4. Capiteles de las semicolumnas

Las bolas son muy habituales en el último Gótico, estando presentes en la iglesia de Hornos y en muchos de los templos de las encomiendas santiaguistas de la Sierra de Segura. Son un elemento decorativo de origen románico que comenzó a usarse en Jaca (Huesca), recurso generalizado en el camino de Santiago, muy común en la arquitectura hispana durante el Románico y el Gótico. Igualmente contamos con ejemplos más o menos cercanos en el Reino de Granada, caso de los capiteles de la galería-mirador del castillo de Vélez Blanco (1506-1515), en el norte de la provincia de Almería, población perteneciente al partido de Baza y en los capiteles de las columnas de las galerías de los convalecientes del Hospital Real (1511-1522) en la capital del reino ${ }^{24}$.

En cuanto a las representaciones vegetales, tomados de la flora del país, son muy usuales en el Gótico. Se presentan aquí alineadas, rítmicamente repetidas a lo largo del capitel, anulando el sentido naturalista en el que suelen inspirarse. Son cuatro hojas de formato trilobulado configurando una especie de $\mathrm{X}$ en torno a un botón central.

iglesias construidas en la Sierra de Segura y otros derivados de formar parte de la misma encomienda: plantas, elementos estructurales y ornamentales.

${ }^{23}$ Lázaro, 2003: 515- 516.

${ }^{24}$ La utilización de las bolas góticas está presente igualmente en la de la portada interior del Hospital Real y en las columnas entorchadas y arcos de la Lonja de la ciudad de Granada. 
Mención aparte, por su notable impronta, merece la hermosa bóveda gótica que cubre la capilla, siguiendo un diseño habitual a finales del siglo XV y a comienzos del XVI, solución arquitectónica que indica la vigencia de gustos y técnicas constructivas todavía medievales. Los arcos de medio punto y las nervaduras de piedra, que la configuran, contrastan vigorosamente con la blancura de los plementos.

Los nervios dibujan una estrella de nueve claves y de ocho puntas, cuatro largas en las diagonales y cuatro cortas, a modo de pies de gallo rectos que parten de las claves de los arcos de cabeza. Un abovedamiento de simbología cristiana (aludiendo a la bóveda celeste, al sacrificio de la misa, a la simbología del número 8, etc.). Las primitivas comunidades cristianas interpretaban las estrellas como símbolo de la divinidad de Cristo, emparentando la de ocho picos con la creación y la resurrección.

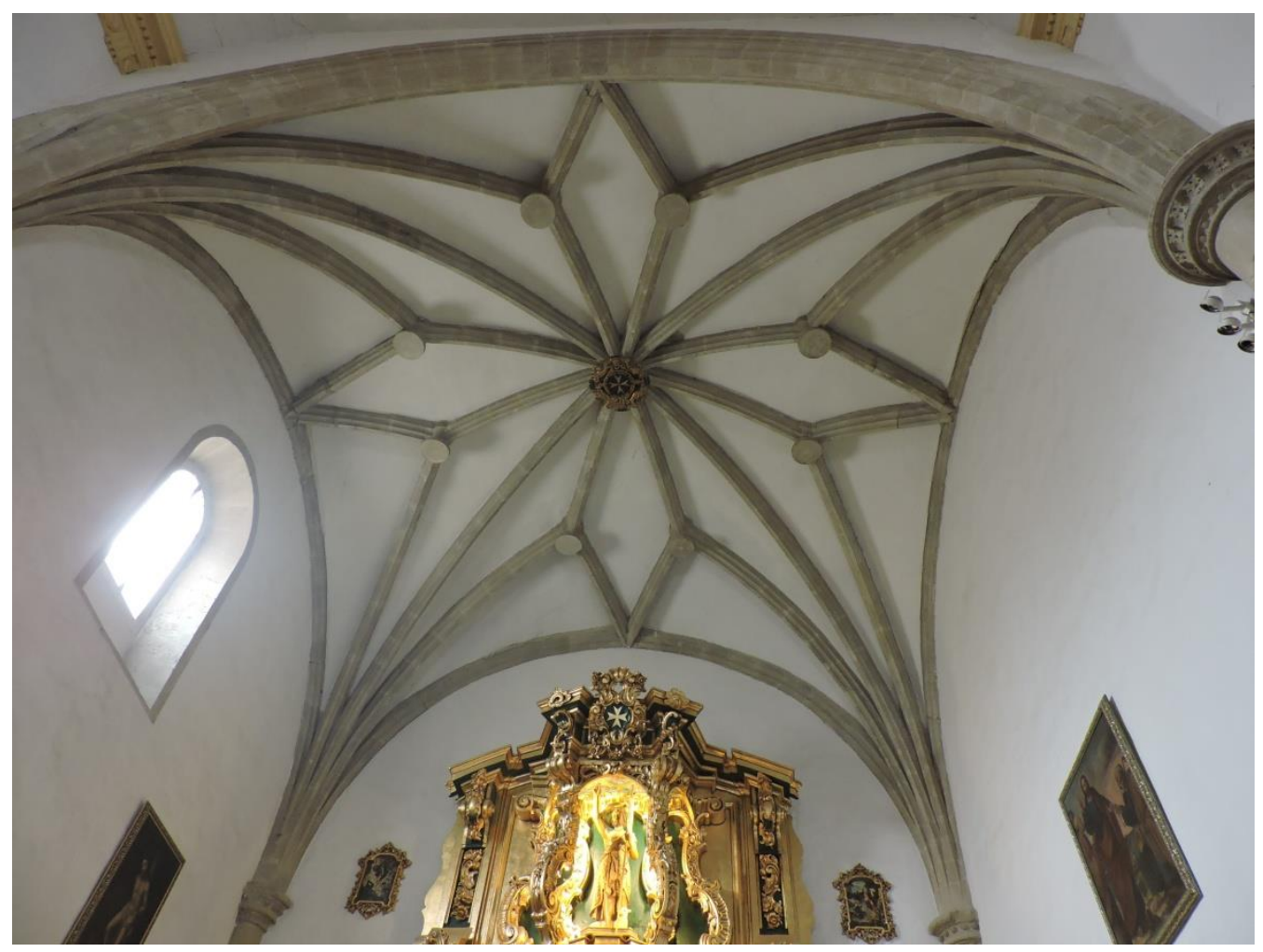

Fig. 5. Bóveda estrellada de la capilla mayor.

Según Javier Gómez la estrella de ocho puntas tiene un origen remoto. Se traza, por primera vez, en las capitulares inglesas de finales del siglo XII y es difundida por los cistercienses en el continente europeo, especialmente en la zona del Rhin ${ }^{25}$. Desde allí debieron ser importadas a nuestro país por los maestros alemanes y flamencos.

En España tenemos bóvedas similares por muchos de los reinos peninsulares ${ }^{26}$, señalando aquí el ejemplo más evidente y cercano que hemos localizado. Nos referimos a la bóveda de

\footnotetext{
${ }^{25}$ Gómez, 1998: 79-80. Construidas en Inglaterra sobre plantas circulares y poligonales...

${ }^{26} \mathrm{La}$ ausencia absoluta de nervios curvos, hecho presente en esta bóveda, es una característica dominante de la escuela de cantería levantina. Dentro del ámbito levantino, en concreto el valenciano, podemos encontrar bóvedas de nueve claves, en la sala capitular del monasterio de la Valldignala, la iglesia
} 
la capilla mayor de la iglesia de Hornos en el noreste jienense, construcción con la que mantiene más similitudes, las analizadas hasta el momento y las que veremos a continuación ${ }^{27}$.

En la clave central un florón que muestra una cruz de Malta tallada en madera y policromada. Desconocemos cuando se colocó dicha pieza, siendo habitual en el último Gótico utilizar temas icónicos de índole religiosa en la decoración de las claves. De no colocarse expresamente en la Edad Moderna puede sea un elemento reutilizado tras la destrucción del retablo en la Guerra Civil.

La cruz de Malta es el emblema de los caballeros hospitalarios de Jerusalén y de San Juan. Presenta cuatro puntas de flechas apuntadas al centro, con lo que resulta una cruz de ocho picos. Para algunos historiadores la cruz tiene un sentido simbólico. Unos apuntan a las ocho bienaventuranzas $^{28}$, las virtudes que han de tener los que alcanzan el reino de los cielos y otros afirman que se trata de las ocho virtudes de la caballería antigua.

\section{Exterior}

El aspecto exterior de la capilla es macizo y sobrio. Apenas puede apreciarse pues se encuentra encajonada entre edificios (capilla de los Alcaraz, casa parroquial y otras construcciones...). Para poder observar parte de la misma hay que hacedlo desde cierta altura, desde la Alcazaba.

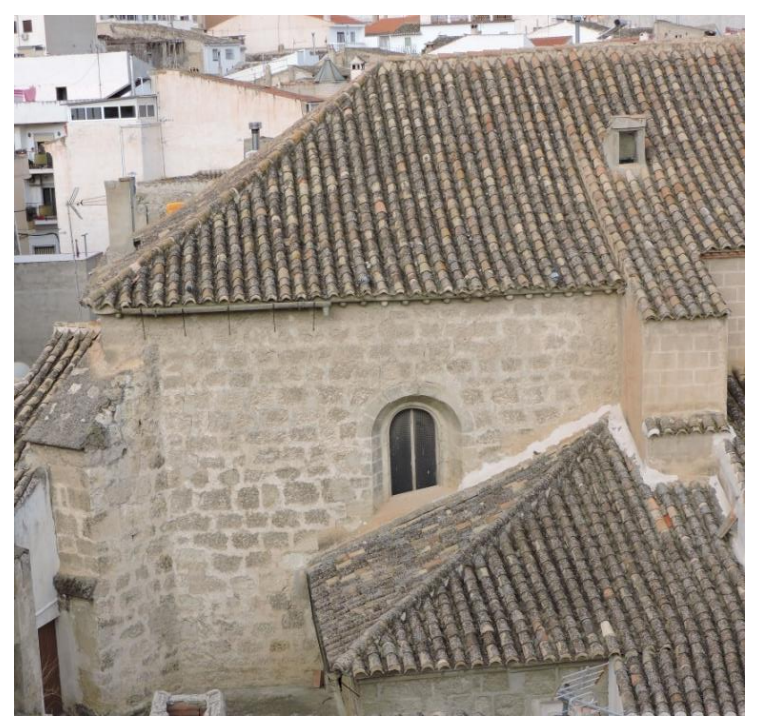

Fig. 6. Capilla. Vista desde el exterior.

de Biar, el coro del templo de Mora de Rubielos y la bóveda de la capilla de la Lonja de Valencia -de finales del siglo XV-.

${ }^{27}$ En la provincia de Jaén podemos contar bóvedas similares, caso de las de la iglesia de San Ildefonso en la capital. Aunque estas son anteriores y se levantaron sobre arcos apuntados, no sobre arcos de medio punto.

${ }^{28}$ Bienaventuranzas: Bienaventurados los pobres de espíritu, porque de ellos es el reino de los cielos; Bienaventurados los mansos porque ellos poseerán la tierra; Bienaventurados los que lloran porque ellos serán consolados; Bienaventurados los que tienen hambre y sed de justicia, porque ellos serán saciados; Bienaventurados los misericordiosos, porque ellos alcanzarán la misericordia; Bienaventurados los limpios de corazón, porque ellos verán a Dios; Bienaventurados los pacíficos, porque ellos serán llamados hijos de Dios; Bienaventurados los que padecen persecución por la justicia, porque de ellos es el reino de los cielos. 
Destaca por su formato cúbico de gran volumen totalmente desornamentado, remarcado por cuatro estribos, angulados en las esquinas de la cabecera. Presenta muros de sillería un tanto irregular con llagas que contrastan con el color de la piedra. Los paramentos quedan rematados por una cornisa de piedra labrada, adornada con bolas góticas.

Los contrafuertes son de sección rectangular, lisos y firmes, una solución escogida para resistir el empuje de la bóveda interior. Ascienden rectos, desde el suelo hasta acabar por debajo de la cornisa, disminuyendo en anchura en el último tercio. Quedan rematados por taludes de piedra labrada para la caída de las aguas.

Recorre toda la cabecera un alero con bolas góticas, motivo decorativo muy del gusto del siglo XV y principios del XVI, aplicándose con frecuencia en la ornamentación arquitectónica de los distintos reinos peninsulares. Aunque es un recurso propio del románico su uso se generalizó durante la alta Edad Media.

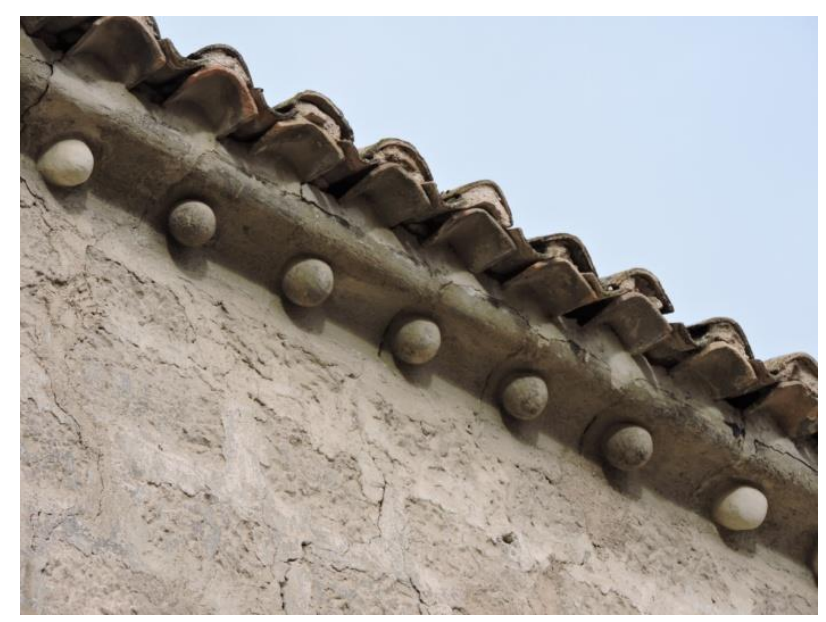

Fig. 7. Alero. Bolas góticas.

Esta tipología de cornisas vuelve a relacionar esta construcción con lo que se estaba haciendo en el sudeste español y en las poblaciones de la orden de Santiago en distintas encomiendas de la Sierra de Segura: Hornos, Yeste, Socovos, Letur, Lietor. Una de las cornisas con la que mantiene más similitudes es la de la capilla mayor de la iglesia de Hornos, con la que guarda una estrechísima relación estilística, construcción levantada por Juan de Mújica ${ }^{29}$.

En Granada, la capital del reino, rematando cornisas de templos, las encontramos en la Capilla Real, obra de Enrique Egas (1505-1515) dedicada a los Santos Juanes.

\section{Tracista y ejecutores de la capilla}

Desconocemos quién diseñó esta notable capilla. Debió ser trazada por alguno de los maestros tardogóticos que estaban despuntando en el panorama arquitectónico del sudeste español, en las comarcas limítrofes de las provincias de Jaén, Granada, Albacete y Murcia, territorios dependientes a nivel religioso del arzobispado de Toledo y del obispado de

\footnotetext{
${ }^{29}$ Vistas desde fuera, aunque la bastetana este rodeada de edificaciones, parece que estamos ante el mismo templo.
} 
Cartagena, entidades territoriales que estuvieron relacionadas por distintos vínculos, especialmente por su cercanía.

Cualquiera de las conjeturas aquí establecidas, basadas únicamente en deducciones, ante el vacío documental existente, hace movernos inevitablemente en el terreno de la hipótesis. En este sentido es importante recordar dos hechos que marcaron a estos territorios y que están relacionados con los límites de ambas diócesis en el siglo XVI, los cuales no se correspondían con los actuales. En primer lugar, señalar que la diócesis de Cartagena, con sede en Murcia, se extendía, más allá de los actuales límites, por poblaciones de Murcia, Albacete y Alicante, comarcas dónde destacaba la presencia de orden militar de Santiago, hecho justificado por ser tierra de frontera hasta la conquista del Reino de Granada ${ }^{30}$. En segundo lugar, indicar que las comarcas de Baza y Huéscar dependieron, como todo el Adelantamiento de Cazorla (Jaén), de la archidiócesis de Toledo hasta 1544, año en que se firmó la Concordia de Valladolid. A partir de ese momento la Abadía bastetana pasaba a depender de forma definitiva del obispado de Guadix.

Ante la construcción del templo de San Juan el cabildo abacial bastetano, y los beneficiados de dicha iglesia, debieron tener presente a los maestros más destacados que estaban trabajando en la ciudad y en la zona de influencia de la Abadía, desconociendo en este momento quién presentó las trazas.

Aunque en líneas generales la tipología empleada está muy relacionada con lo que se estaba haciendo a finales del XV, y primer tercio del XVI, por gran parte de la península, señalamos a un artífice que estaba desarrollando su labor constructiva en el sudeste español, apuntando nuestra investigación al tracista de la iglesia de Hornos de Segura. No olvidamos en ningún momento a los maestros que deambulaban por el sur de Castilla La Mancha y el Reino de Murcia, y que se acercaron a estos territorios ${ }^{31}$. Las relaciones cronológicas y filiaciones estilísticas de la capilla mayor con la del templo parroquial de la última población comentada hacen pensar que en su trazado pudo intervenir el mismo cantero ${ }^{32}$.

Lo que hemos podido constatar documentalmente es la presencia, en el primer tercio del siglo XVI, momento en el que se levantó la capilla, de varios maestros de cantería muy cotizados: Juan Caballero, Rodrigo de Lamíquiz y Juan de Mújica. En cuanto al primero, de probable origen murciano, y del que apenas hemos localizado documentación, señalar que estuvo presente en la segunda década del siglo, realizando el puente sobre el río Barbata (1516) y dirigiendo otras obras a nivel civil (rambla) y quizás religioso.

En la década de los veinte tenemos deambulando por Baza a Rodrigo de Lamíquiz, posiblemente uno de los artistas más destacados del momento trabajando para distintas poblaciones del sudeste español y en la década de los treinta a Juan de Mújica. Ambos estuvieron en nuestra ciudad, y en poblaciones de las encomiendas santiaguistas de la Sierra de Segura, cuyas construcciones tienen elementos en común con la capilla mayor que estamos viendo.

El primero de ellos, Rodrigo de Lamíquiz, trabajó en Baza en la década de los años veinte, en varias poblaciones de Albacete y tal vez en el nordeste jienense, véase por ejemplo a un

${ }^{30}$ El Papa Nicolás IV trasladó la sede a la ciudad de Murcia en 1289, a lo que se sumó la autorización real de Sancho IV en 1291 estableciéndose la catedral en la iglesia de Santa María la Mayor de Murcia. El territorio de la diócesis se extendería, más allá de sus actuales límites, por territorios de Andalucía, Albacete y Alicante, con presencia muy importante de las órdenes militares, fundamentalmente la de Santiago.

${ }^{31}$ Sánchez, 1996: 132.

${ }^{32} \mathrm{U}$ otro maestro cercano. 
maese Rodrígo, quizás Lamíquiz, levantando la iglesia de Segura de la Sierra en 1525. El otro maestro de cantería es Juan de Mújica, quien dirigió las obras del templo de Hornos en los años veinte y del que tan sólo tenemos constancia de su presencia en Baza en los años treinta. Aunque no lo descartamos como posible tracista, no ha parecido, hasta el momento, ningún dato sobre su llegada a nuestra ciudad con anterioridad. Dicho maestro podría haber estado trabajando en el círculo de Francisco de Luna en Villanueva de los Infantes (Ciudad Real)

Sobre Lamíquiz, del que sabemos que estuvo a principios de los años veinte en Baza (momento en el que intuimos que se presentaron las trazas y se ejecutaron las obras), presentaremos unas pincelas biográficas, apoyándonos en publicaciones anteriores, especialmente en las reflexiones de la profesora Lázaro Damas, quien, además de aportar nuevos datos y plantear varias hipótesis, recoge lo publicado hasta el momento.

\section{Rodrigo de Lamíquiz}

Cómo afirma dicha historiadora, Rodrigo de Lamíquiz es un maestro cuya dimensión arquitectónica está aún por descubrir. No ha habido unanimidad a la hora de transcribir su apellido pues lo podemos encontrar escrito de varias formas por distintos investigadores (Lamíquez, de la Mites) ${ }^{33}$. En este periodo histórico su actividad estaba vinculada a un territorio más o menos amplio que comprende parte de las provincias de Albacete, Jaén y Granada. Aparece relacionado con algunas fábricas parroquiales administradas por la Orden de Santiago en las dos primeras provincias mencionadas, bien directamente relacionado con sus obras, caso de Yeste (1523-1527), o como perito, caso de Letur, ofreciendo sus informes y dictámenes al respecto ${ }^{34}$. En los años veinte debía ser un maestro de cierta edad, de trayectoria consolidada, al menos eso puede deducirse del hecho de que su presencia en Baza se deba a una invitación del cabildo municipal para levantar el puente de Barbata ${ }^{35}$. Es más, para Lázaro Damas podría ser su tracista.

En Yeste se encontraba cuando el ayuntamiento bastetano acordaba llamarlo con la finalidad de que viese las obras realizadas en el mencionado puente (06/09/1521). La presencia del maestro se hizo efectiva en Baza el 3 de octubre de ese mismo año.

Con su llegada debió abrirse el camino a otros canteros con los que estuvo vinculado, caso de Pedro de Urrutía ${ }^{36}$, y Juan de Alzaga, maestros que seguirán trabajando en la ciudad hasta el terremoto de 1531, momento en el que probablemente fallecieron, monopolizando muchas de las obras más destacadas de la década de los años veinte: puente del río Barbata, iglesia colegial, capilla de Juan Romero en el templo de Santiago... Estos tres maestros debieron formar una cuadrilla, cuyo cabecilla pudo ser Lamíquiz, autodenominándose en varias ocasiones compañeros ${ }^{37}$. Debieron formar un equipo de trabajo, "una compañía" a través de vínculos familiares o vecinales de canteros procedentes de la misma zona, de la provincia de Vizcaya. Este tipo de asociaciones, habitual en Cantabria y en el País Vasco,

\footnotetext{
${ }^{33}$ Barrio/Moya, 1981: 87. Para nosotros se trata del apellido Lamíquiz. Pudo ser pariente de Pedro de Lamíquez. Dichos autores nos mencionan a un cantero llamado Pedro Lamíquiz, vecino de la anteiglesia de San Miguel de Mendata. Dicho maestro se comprometía, con su tío Pedro de Olave, a continuar las obras de la catedral de Calahorra, desde el crucero hasta la puerta de poniente, el 15 de noviembre de 1518.

${ }^{34}$ Gutiérrez, 1987: 134.

35 Tristán, 2013: 88.

${ }^{36}$ Pedro de Urrutia levantó la capilla del ganadero Juan Romero, reedificada tras el terremoto de 1531, con la que presenta varios paralelismos. Este cantero debió participar en las obras de los años veinte en la iglesia de San Juan, quizás en la capilla mayor.

${ }^{37}$ Lázaro, 2001: 519-521.
} 
implicaba una serie de obligaciones para sus miembros, repartiéndose el trabajo contratado, las decisiones y las ganancias.

\section{Retablo}

Concluida la construcción de la capilla era necesario levantar el retablo mayor, que dotado de un adecuado programa iconográfico, proclamase la gloria de San Juan Bautista, titular bajo cuya advocación se encontraba el templo, contribuyendo a la educación religiosa de la población del barrio, mayoritariamente morisca, remarcando la importancia del bautismo para el cristianismo y para la salvación de las almas.

Aunque la capilla se edificó en el primer tercio del siglo XVI no será hasta finales de dicha centuria cuando se consiga levantar el retablo. Poco a poco los feligreses fueron aportando pequeñas cantidades ${ }^{38}$. Más de setenta años habrían de pasar para que la empresa se llevase a cabo. Es muy probable que la escasez de recursos económicos de la parroquia, acentuada tras la sublevación de los moriscos (1568-1570), retrasase el proyecto definitivo.

En 1598 se contrataba su construcción, descociéndose hoy en día si se ejecutó de forma íntegra o tan solo el primer cuerpo por falta de caudales ${ }^{39}$. En el siglo XVIII se tomo la decisión de contar con un nuevo retablo, reutilizando parte del anterior, adaptándolo a una traza barroca, llevándose a cabo entre 1752 y 1764.

El retablo que llegó hasta la Guerra Civil, centrado en torno a San Juan Bautista, y la Virgen del Carmen, debió conservar del original del siglo XVI las potentes columnas del primer cuerpo y varios paneles tallados que representaban a San Juan, así como fragmentos del retablo barroco: la hornacina central del segundo cuerpo.

A continuación, realizaremos una descripción del diseño del quinientos, del que se conservan las condiciones y presentaremos una hipótesis de la obra realizada a mediados del setecientos con los escasos datos obtenidos en el archivo de protocolos. Probablemente estamos ante una obra híbrida que presentaba dos cuerpos con

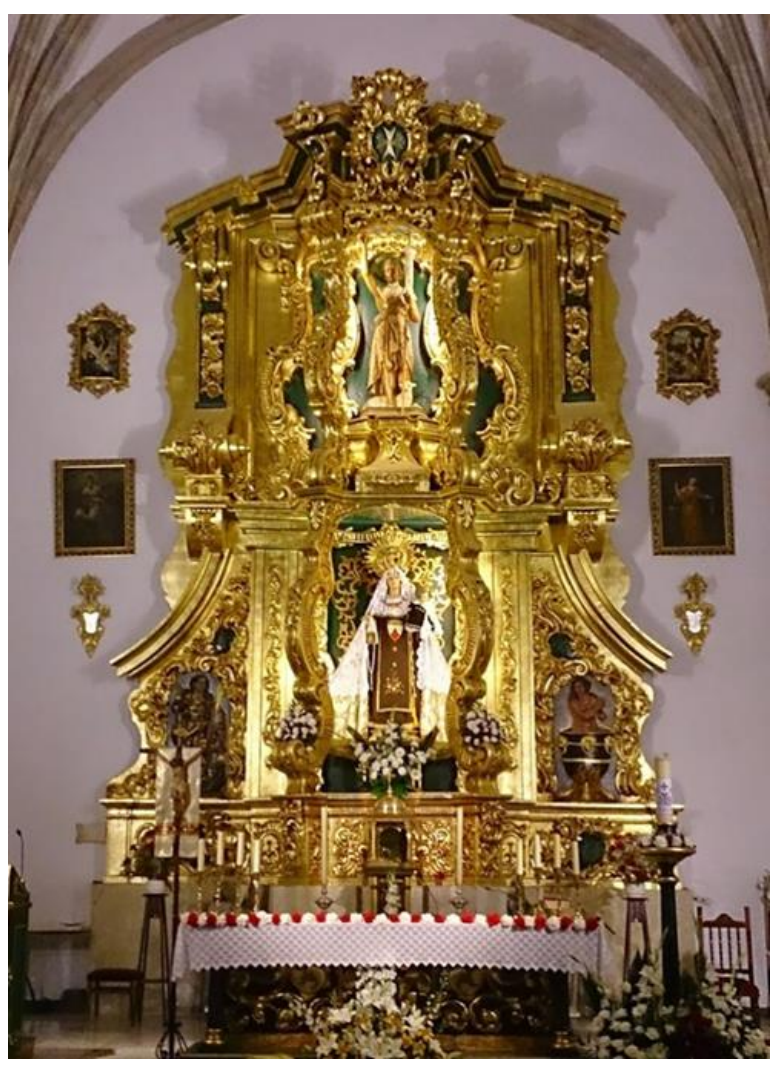

Fig. 8. Retablo. Vista general. elementos de dos periodos estilísticos.

\footnotetext{
${ }^{38}$ En 1545 Álvaro de Alcaraz, mayordomo de la fábrica, donaba 10.000 maravedíes para la construcción del retablo, dinero que retiró posteriormente.

${ }^{39}$ Dado que estamos en el terreno de la hipótesis, por haber desaparecido esta obra en la Guerra Civil, decir que desconocemos si el segundo cuerpo del retablo, el trazado a finales del XVI, no se realizó. Quizás el mayordomo confió demasiado en que iba a conseguir, las limosnas que necesitaban para terminarlo, 100 ducados. La falta de recursos económicos fue algo habitual en la Edad Moderna.
} 


\section{Proyecto renacentista}

Será a finales del siglo XVI cuando se llamará a los Freila, saga de artistas de origen madrileño asentada en Guadix, la capital del obispado, para levantar el retablo. Dicha dinastía había llegado a la ciudad en 1597 para labrar los retablos de las capillas del crucero de la iglesia conventual de San Jerónimo. Gabriel de Freila, y su hijo Miguel, concertaban el 1 de julio de 1598, la realización del retablo mayor de la iglesia de San Juan, el cual debía estar

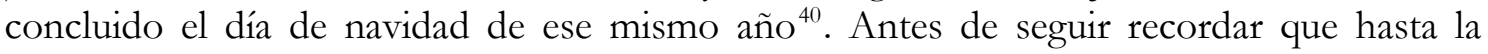
publicación de este artículo todos los investigadores que han escrito sobre esta obra han seguido el error de Luis Magaña, historiador local, quién aseguraba que era una obra de Gabriel y su hijo Pedro ${ }^{41}$.

Para apreciar esta obra, dado que hasta el momento no ha aparecido ninguna documentación gráfica, hay que tener en cuenta las condiciones contempladas en el contrato. Debió trazarse dentro de un lenguaje formal basado en la monumentalidad y el protagonismo rotundo de la arquitectura a través de la utilización de las columnas de corte clasicista que estructuraban los dos cuerpos y por la elegante y sugerente distribución de elementos iconográficos relacionados con episodios de la vida de San Juan Bautista ${ }^{42}$. Todo ello siguiendo las características de los Freila, artistas pertenecientes a la segunda generación de escultores y retablístas romanistas del manierismo español.

La probable similitud entre este retablo, el de la iglesia de Santiago de Baza, construido en 1633 (destruido en la Guerra Civil), bajo las trazas de Juan de Freila y el de éstos con varios de la provincia de Córdoba, tanto a nivel compositivo como decorativo, hace necesario mencionar a Juan y a Pedro Freila de Guevara, los otros hijos de Gabriel, artífices que trabajaron en el entorno granadino y cordobés ${ }^{43}$.

El retablo había de constar de seis varas de ancho y nueve de alto y tendría un coste de 400 ducados, contando la fábrica con 300 ya reservados para llevarlo a cabo, esperando recibir el resto en limosnas de los parroquianos. Los maestros aportarían la madera necesaria para hacer los andamios y labrar las distintas piezas. Esta debía estar seca, buena y limpia, sin nudos, proveniente de los montes de Baza o Huéscar.

$\mathrm{Su}$ formato reflejaba, a grandes rasgos, elementos comunes a muchas obras de este periodo. Estaba articulado en dos cuerpos divididos en tres calles por cuatro columnas, estriadas con basas y capiteles, siendo la calle central más ancha. Sobre las columnas, con sus respectivas traspilastras, se apoyaban sendos entablamentos con arquitrabe, friso y cornisa. Se había de coronar el segundo cuerpo por un frontón triangular que debía contener la figura del Padre Eterno.

Las distintas escenas del programa iconográfico debieron encajar, de forma armónica, con la ornamentación arquitectónica clasicista, con las columnas que enmarcaban los mediorelieves y varias tallas de bulto redondo.

El banco había de tener una vara de alto, debiéndose ubicar, entre los pedestales, un apostolado completo de medio relieve, situando a San Pedro y San Pablo en el centro, a un lado y al otro del sagrario, en cuya puerta debía estar la imagen del Salvador.

\footnotetext{
40 APG, Granada, Baza, Martín Ordoñez, 1598, ff. 193-197. A partir de 1 de junio se le iría pagando 20 ducados mensuales a los escultores. Una vez terminado y entregado se le pagarían los otros 150 ducados.

${ }^{41}$ En el taller de los Freila estaba Gabriel y sus tres hijos: Pedro, Juan y Miguel.

42 Presentando a los doce apóstoles en el banco, de más de medio relieve.

${ }^{43}$ Valverde, 1977: 169-200.
} 
Las calles del primer cuerpo estaban divididas por cuatro columnas de media vara de ancho y tres de alto. Quedaba coronado por un entablamento clásico con friso decorado con romanos de talla y rostros de serafines en los resaltos.

Una observación importante sobre la calle central de este cuerpo y del siguiente. En las condiciones del contrato se estipulaba la necesidad de acomodar, en los intercolumnios centrales de ambos cuerpos, varios elementos que ya estaban realizados y dorados. Los ensambladores sólo tendrían que hacerle los retoques necesarios para que encajasen.

Intuimos que estos elementos son parte del retablo dedicado a San Juan, Santa Ana y San José elaborado en 1595 por el maestro local Juan Antonio para Martín Ruiz, herrero de la ciudad. Dicho señor, tras una demanda mantenida con el artista, lo cedió a la iglesia parroquial $^{44}$. Deducimos, aunque no disponemos de datos para demostrarlo, que los beneficiados del templo decidieron aprovechar parte de la obra recibida, incorporándola al nuevo retablo.

En calle central del primer cuerpo los Freila habían de ensamblar la hornacina destinada a ubicar la imagen de San Juan en talla, todo ello ya policromado y dorado. Para que encajase adecuadamente en el hueco que le correspondía había de adaptarse, ensanchando las jambas. Los maestros habrían de reutilizar igualmente dos columnas y una cornisa doradas para enmarcar la hornacina, pudiendo recurrir a la utilización de los recuadros para revestir los espacios vacios de esta calle ${ }^{45}$.

Juan Antonio, quizás "el viejo", su padre, estuvo vinculado con la iglesia parroquial de San Juan al menos desde la década de los sesenta, momento en el que se encargó de la pintura y dorado de las cubiertas del cuerpo de naves de este templo tras la caída y fallecimiento del pintor Francisco López (1562) ${ }^{46}$. El 7 de noviembre de 1596 el presbítero Alonso del Río había concertado con Juan Antonio el dorado y pintura de un tabernáculo y de un retablo, quizás el cedido por Martin Ruiz ${ }^{47}$.

En las calles laterales presentaba un programa destinado a ilustrar algunos pasajes significativos relacionados con la historia de San Juan Evangelista: La visitación de la Virgen María a su prima Santa Isabel, madre del santo titular, a la derecha y el nacimiento de San Juan Bautista a la izquierda, ambas de medio relieve.

En la calle central del segundo cuerpo los Freila debían encajar dos columnas con sus pedestales y cornisa, ya labradas y doradas, aunque la cornisa había de alargarse lo que faltase. La caja de esta calle central había de quedar acabada para que se pudiera dorar y pintar. Dentro debía colocarse el Cristo crucificado con la Virgen y San Juan de bulto redondo, formando un Calvario ${ }^{48}$. En los tableros de las calles laterales se habían de representar el bautismo en el río Jordán a la derecha y el martirio, la degollación de San Juan, a la izquierda, los dos de más de medio relieve.

Se coronaría el retablo con el frontón triangular con un medio relieve de Dios padre, en formato de busto. Como remate había de tener en el centro una cruz de la encomienda de San Juan y a ambos lados sendos escudos.

\footnotetext{
${ }^{44}$ APG, Granada, Baza, Martín Ordoñez, 1595, ff, 65-75.

${ }^{45}$ En el contrato se menciona una caja. Entendemos que caja es hornacina.

${ }^{46}$ Segura/Valero, 2014: 387-389.

${ }^{47}$ APG, Granada, Baza, Martín Ordoñez, 1596, f. 250.

${ }^{48}$ En el contrato con Juan Antonio, había realizado el retablo con Santa Ana, San Juan Bautista y San José.
} 
El inventario elaborado en 1918 describe un retablo estructurado por cuatro columnas, disponiendo en los intercolumnios 6 mediorelieves alegóricos a la vida de San Juan, 2 más de los especificados en este contrato.

\section{El retablo barroco}

A mediados del siglo XVIII la fábrica decidió levantar el retablo definitivo adaptado al nuevo estilo, el Barroco, construyendo y/o remodelando el primer cuerpo alrededor de 1752 y levantando el segundo en torno a 1764, cuyo diseño, en líneas generales, es el que se repite hoy día en los dos cuerpos ${ }^{49}$.

El 9 de octubre de 1752 Francisco Martínez Sigüenza, beneficiado de dicha parroquia, declaraba que se le debían 100 reales de la obra del retablo al tallista Pedro Montoro, el cabeza de una de las sagas de retablistas más destacada de la ciudad y del norte del Reino de Granada. Solicitaba que no le pagasen hasta que no remátese el primer cuerpo pues le faltaba por colocar varias piezas de talla ${ }^{50}$.

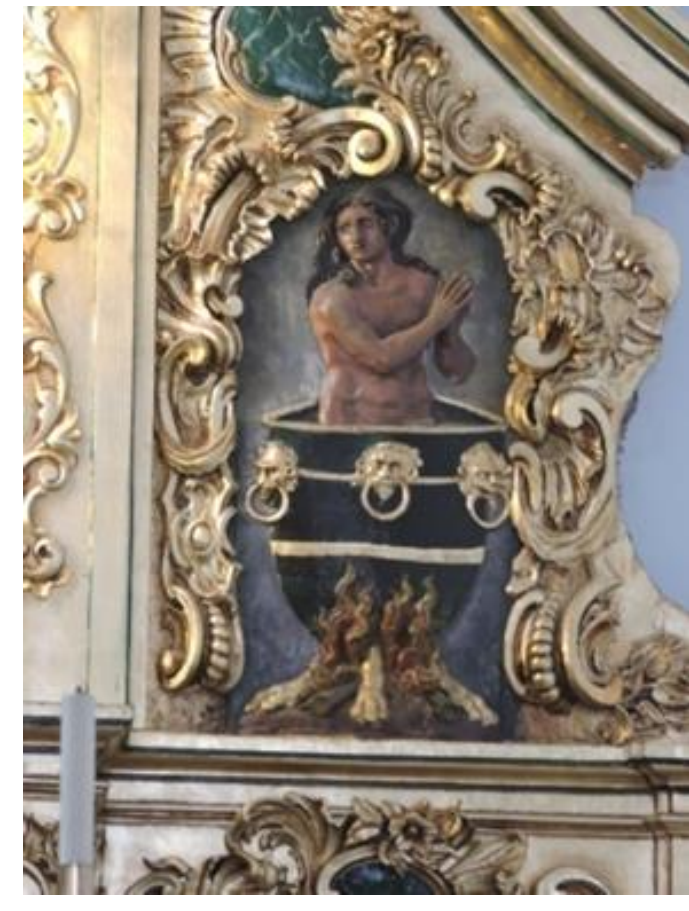

Fig. 9. Detalle. San Juan en la caldera.

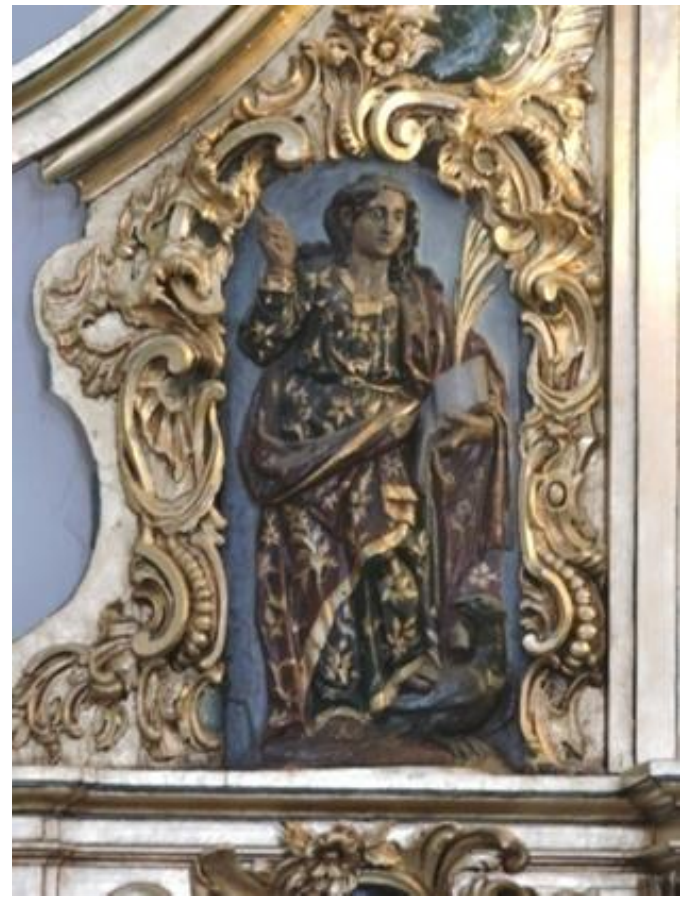

Fig. 10. Detalle. San Juan escribiendo el Apocalipsis.

Desconocemos si Montoro reutilizó gran parte del retablo renacentista, la estructura arquitectónica integrada por las potentes columnas que lo configuraban, con sus entablamentos respectivos, modificando principalmente las hornacinas centrales al gusto barroco y recuperando el programa iconográfico renacentista relacionado con San Juan en los mediorelieves dispuestos en los intercolumnios, caso del de San Juan en la caldera y el de

${ }^{49}$ El segundo cuerpo del retablo del periodo Barroco coincide, en esencia (hornacina), con el cuerpo actual. Muy probablemente contaba con los relieves (ubicados hoy en el primer cuerpo) a ambos lados.

${ }^{50}$ APG, Granada, Baza, Juan de Arnedo, 1752, ff, 65-75. Testamento de Francisco Martínez Sigüenza. Además, Pedro Montoro debía de asentar la puerta de la sacristía que estaba sin colocar. 
San Juan escribiendo el Apocalipsis ${ }^{51}$, los únicos que han sobrevivido a la Guerra Civil. La profesora Lázaro considera estos dos relieves son de este periodo, asegurando que siguen un canon cercano a Pablo de Rojas ${ }^{52}$.

Lo que sorprende es que estos dos mediorelieves representen episodios de la vida de San Juan Evangelista, no los de San Juan Bautista, los contemplados en el contrato del siglo XVI. El de la epístola exhibe el primer capítulo de los "milagros de Juan", recogiendo la prueba que hubo de soportar cuando fue arrojado a una caldera de aceite hirviendo por negarse a renegar de Cristo y cesar de predicar, saliendo más fresco y lozano que entró. Después de estos sucesos fue desterrado a la isla de Patmos donde escribió el Apocalipsis, el tema del segundo tablero conservado.

Habiendo pasado algo más de una década de la construcción (y/o remodelación) del primer cuerpo Pedro Carrillo y Gutiérrez, canónigo de la iglesia colegial y secretario de la venerable Hermandad del Carmen, sita en esta parroquia, afirmaba que se había tratado el levantamiento del segundo cuerpo, proponiendo aprovechar la ocasión para incorporar en el mismo una nueva devoción, la Virgen del Carmen, hecho comunicado a la hermandad el 31 de mayo de $1764^{53}$. A cambio dicha institución contribuiría con 200 ducados de vellón para elaborar el trono y para dorar y alhajar el retablo, cuyos trabajos estaban finalizando. Para sufragar los gastos de esta intervención se vendió la lámpara de plata que había iluminado dicha imagen hasta ese momento ${ }^{54}$. La hermandad aportaría 2.200 reales para finalizar la construcción.

El 24 de julio de 1772, tras llevar muchos días paralizados los trabajos del dorado, sin caudal para su conclusión, Francisco de Sola y Aparicio, mayordomo de la fábrica, solicitaba ante el provisor y vicario de la Abadía dos censos de 1.240 maravedíes, los de las memorias que fundaron doña Ana de Medrano y Sebastián de Segura, los cuales fueron redimidos, aplicando dicho caudal en su terminación ${ }^{55}$.

Desgraciadamente el retablo fue destruido en el verano de 1936 junto con el resto del patrimonio mueble de la iglesia. El que hoy podemos contemplar es una recomposición realizada tras la Guerra Civil en el que se incluyeron los escasos restos conservados de los retablos de los siglos XVI y XVIII.

La obra la debió trazar y ejecutar Pedro Montoro, destacado tallista de origen cordobés asentado en la Baza, artífice que cubrió el espacio dejado en la ciudad tras el fallecimiento de Gabriel Jiménez en la década de los cuarenta, el último representante destacado de la saga de los Jiménez.

${ }^{51}$ Antes de proseguir una observación con respecto a estos medios relieves. En el retablo contratado a finales del XVI sólo constan cuatro relieves (Visita de la Virgen a Santa Isabel, nacimiento de San Juan, el bautismo en el Jordán y el martirio del santo). Sin embargo, en la descripción del retablo de principios del siglo XX se señalan seis, dos más que lo contratado en un principio. Desconocemos si los dos relieves de más fueron una ampliación al contrato de 1598 o se realizaron en el siglo XVIII. En el contrato de 1598 no consta relieve alguno de San Juan Evangelista, sólo se habían de realizar episodios de la vida de San Juan Bautista.

52 Lázaro, 2013: 136.

${ }^{53}$ APG, Granada, Baza, 1764, Manuel Sánchez de la Castellana, ff. 148-148v.

${ }^{54}$ APG, Granada, Baza, 1764, Baza, Manuel Sánchez de la Castellana, ff. 148-153. El 22 de julio de ese año se afirmaba que se había comunicado al obispo de la diócesis, Francisco Alejandro de Bocanegra y Gibaja, las condiciones de lo tratado en cabildo, además de solicitar su autorización.

55 APG, Granada, Baza, Pedro José Romero, 1772, pp. 140-141. El tallista Lorenzo Montoro estuvo casado con Tomasa Fernández Prieto. Se da la circunstancia que dos de los testigos de esta escritura fueron Matías Fernández Prieto y Pedro Prieto, parientes directos de la mujer de este maestro, el primogénito de Pedro Montoro. 
Hasta el momento poco conocemos de esta linaje artístico cuyo taller fue uno de los de más renombre desde mediados del siglo XVIII hasta finales de la década los ochenta, momento en el que debió fallecer el fundador y su taller fue desbancado, en gran medida, por el de José Ortiz Fuertes, artífice oriundo de Játiva (Valencia).

Pedro Montoro aparece registrado en el Catastro de la Ensenada $(1752)^{56}$ como maestro tallista junto a su hijo Lorenzo, con 31 y 8 años respectivamente. Desconocemos cómo llegó a Baza, si contratado por su fama o en busca de trabajo, aprovechando el vacío creado tras el fallecimiento de Gabriel Jiménez. Una vez instalado en la capital abacial casó con la bastetana Teresa de Torres.

El dato más antiguo conocido sobre este taller nos lo proporciona Manuel GómezMoreno González al atribuirle el retablo de la Virgen del Socorro de la iglesia colegia ${ }^{57}$, obra relacionada a la escuela levantino-murciana por Juan Jesús López-Guadalupe ${ }^{58}$. Otro de sus trabajos relevantes es el retablo de la Concepción para el mismo templo (1772), igualmente vinculado a la escuela murciana de Jaime Bort por José Manuel Gómez-Moreno ${ }^{59}$ y Juan Jesús López-Guadalupe ${ }^{60}$.

En 1781 tasó, y probablemente ejecutó, las obras de carpintería en las reformas, por filtraciones de agua, del templo de San Juan de Baza: la armadura de la nave central, a la altura del coro, y alfarje del evangelio ${ }^{61}$.

En 1784 se le llamaba de la iglesia parroquial de Santa Ana de Guadix para intervenir en el retablo y el camarín del templo, trabajos que había estado llevando a cabo el tallista Torcuato Vergara, actuaciones que rematará Montoro en 1786, tras presentase en la capital del Obispado, una vez finalizados los encargos que había estado realizando en Fiñana (Almería) ${ }^{62}$.

La dimensión artística de dicho artífice, y de su taller familiar, requiere un estudio más profundo y está aún por descubrir. Su valía queda reflejada en la memoria del corregidor Pueyo Sansón (1787) al analizar el panorama artístico del partido de Baza. En la descripción que realiza del mundo de las artes sólo menciona a un maestro tallista, a Pedro Montoro, "insigne dibujante" en cuya habilidad había instruido a sus hijos. Fue una obra de talla suya la que causó "admiración" en en la primera sesión de la Junta General de la Real Sociedad de Amigos del País de Baza celebrada en las casas consistoriales el día 3 de mayo del 1784.

\section{Conclusiones}

La capilla mayor de la iglesia de San Juan de Baza, levantada en el primer tercio del siglo XVI, y su retablo, labrado en torno a 1598, son dos notables obras del quinientos en el norte del Reino de Granada. La construcción sigue una solución habitual en las edificaciones

\footnotetext{
${ }^{56}$ Cano, 1990: 82. El otro tallista censado en el catastro es Torcuato Vergara, del que hemos localizado escasa documentación, estuvo casado con Josefa Alós Vidal, hija del maestro Pascual Alós y de su segunda esposa. No debemos olvidar a los Alós y su origen levantino, deambulando en este periodo entre las altiplanicies, Guadix y Almería.

${ }^{57}$ López-Guadalupe, 1998: 97.

${ }^{58}$ Ibídem.

${ }^{59}$ Gómez-Moreno, 1995:105.

${ }^{60}$ IGM, El historiador muy probablemente recoja lo que le dicen en Baza. Anotando Salvador Montoro. Que nosotros sepamos, en esta familia no había ningún integrante con el nombre de Salvador.

${ }^{61}$ Segura, 2007: 381-386.

${ }^{62}$ Rodríguez, 2011: 143-144.

${ }^{63}$ Archivo Histórico Nacional (AHN, Madrid), Consejos, leg. 1046/13, f. 20.
} 
religiosas del primer tercio del siglo XVI en el sudeste español, en los territorios situados en las encomiendas santiaguistas de la Sierra de Segura, en las provincias de Jaén y Albacete. Estamos ante una capilla tardogótica con algunos elementos que están anunciando, muy tímidamente, la llegada de nuevo estilo, el Renacimiento, apreciándose en su planta y en la utilización del arco de medio punto. Los azares del destino, la Guerra Civil, hicieron desaparecer su magnífico retablo, algunas de cuyas piezas lograron reintegrarse en el retablo levantado tras la finalización del periodo bélico. 


\section{Bibliografía}

Barrio, J.A. / Moya, J. G.: "Los canteros vizcaínos (1500-1800). Diccionario biográfico. II parte”. En: Grupo Espeleológico vizcaníno, (11), Vizcaya, (1981), pp. 173-282.

Cano, G.: Baza 1752. Según las Respuestas Generales del Catastro de la Ensenada. Madrid: Tabapres. (1990).

Castillo, J.: Baza. Guías de Historia y Arte. Granada: Diputación. (2009).

Galera, P.: "Arquitectura religiosa de la Sierra de Segura". En: Anales de la Sierra de Segura, 56, pp. 56-67.

Gómez, J.: El gótico español de la Edad Moderna. Bóvedas de crucería. Valladolid: Universidad. (1998).

Gómez-Moreno, J. M.: “Arquitectura y ornato en la altiplanice granadina durante el siglo XVIII". En: Boletín del Instituto "Pedro Suárez”, (7-8), Guadix, (1994-95), pp. 89-10.

López-Guadalupe, J. J.: "Del Barroco avanzado al Neoclasicismo en la retablística del Setecientos. Apuntes para una monografía". Cuadernos de Arte de la Universidad de Granada, 29 (1998), pp. 89-106.

Gutiérrez, C.: Renacimiento y arquitectura religiosa en la antigua diócesis de Cartagena. Reino de Murcia, gobernación de Orihuela y Sierra de Segura. Murcia. (1987).

Lázaro, M. S.: "Aportaciones documentales para el estudio de la iglesia mayor de Baza y sus primeros maestros de cantería". En: Actas del II Coloquio del Seminario de Estudios "Sociedad, Iglesia y Cultura. Iglesia y Sociedad en el Reino de Granada (ss. XVI-XVIII". Granada: Diputación y Universidad. (2003), pp. 511-523.

Lázaro, M. S.: "Los Freila Guevara. Una familia de escultores accitanos". En: Boletín del Centro de Estudios Pedro Suarez: Estudios sobre la comarca de Guadix, Baza y Huéscar, (26), Guadix, (2013), pp. 129-150.

López, J. J.: "Del Barroco avanzado al Neoclasicismo en la retablística del setecientos. Apuntes para una monografía". En: Cuaderno de Arte de la Universidad de Granada, (29), Granada, (1998), pp. 121-146.

Magaña, L.: (1978). Baza histórica. Baza: Asociación Cultural de Baza y su comarca. (1978).

Martínez, Á. / Tristán, F.: “Toponimia de la Bastitania III (Religiosa)". En: Péndulo (Baza), 5 (2004), pp. 33-65.

Olivera, C.: La actividad sísmica en el Reino de Granada (1487-1531). En: Estudios históricos y documentos. Madrid (1995), pp. 1-112.

Rodríguez, J.M.: "La remodelación barroca de la iglesia de Santa Ana de Guadix". En: Boletín del Centro de Estudios Pedro Suarez: Estudios sobre la comarca de Guadix, Baza y Huéscar, (24), Guadix, (2011), pp. 125-150.

Sánchez J.: "Estudio arquitectónico de las iglesias parroquiales de la encomienda santiaguista de Socovos". En: Al-Basit. Revista de Estudios albaceteneces, (39), Albacete, (1996), pp. 117 155.

Segura, J. M.: Baza, de la Ilustración al Historicismo: urbanismo, arquitectura y artes plásticas. Universidad de Granada (Tesis Doctoral). (2007).

Segura, J. M. / Valero, C.: "La casa de Juan de Araoz y los baños de Gonzalo de Quirós". En: Péndulo (10), Baza, (2009), pp. 61-83.

Segura, J. M. / Valero, C.: "Las cubiertas de madera de la iglesia de San Juan". En: Péndulo, (15), Baza, (2014), pp. 385-399.

Segura, J. M. / Valero, C.: "Las naves y la torre de la iglesia de San Juan”. En: Péndulo, (16), Baza, (2015), pp. 323-337. 
Segura J. M. / Valero, C.: "La capilla de Álvaro de Alcaraz en la iglesia de San Juan de Baza". En: Boletin del Centro de Estudios Pedro Suarez: Estudios sobre la comarca de Guadix, Baza y Huéscar, (17), Guadix, (2015), pp. 77-93.

Tristán, F.: “La puente del Río Barbata. El puente del río de Zújar”. En: Péndulo, (14), Baza (2013), pp. 83-114.

Valverde, J.: "Pedro de Freila Guevara. Un escultor barroco". En: Boletín de Bellas Artes, Sevilla, (5), Sevilla, (1997), pp. 169-200. 